\title{
Ni(II)-PPP Complexes: From the Hydroamination of Activated Olefins to the Synthesis of $\beta$-Amino Acids
}

\author{
Luca Fadini and Antonio Togni
}

\begin{abstract}
Complexes of the type [Ni(PPP)(solvent)] $\mathrm{X}_{2}$ containing ferrocenyl tridentate ligands have been prepared and used as catalysts in the asymmetric hydroamination of activated olefins (i.e. bearing an electron-withdrawing group). In the case of acrylonitrile derivatives the addition of aliphatic amines displayed relatively high activities and moderate enantioselectivity (yields up to $99 \%$, ee's up to 69\%). The reactions were also carried out in various ionic liquids (imidazolium and picolinium salts) with results comparable to those obtained in common organic solvents. Additionally, we describe the conversion of several products to $\beta$-amino acid derivatives.
\end{abstract}

Keywords: Activated olefins · $\beta$-Amino acids · Asymmetric catalysis · Hydroamination · Nickel

\section{Introduction}

The direct addition of amines to olefins is a particularly attractive synthetic approach to secondary or tertiary amines, an industrially important class of products [1]. The hydroamination reaction is weakly exergonic and has a highly negative entropy, and is therefore difficult to catalyze [1][2]. Up to date, no generally applicable systems have been developed. In the special case of the asymmetric addition of amines to olefins [3] only few examples have been reported, based predominantly on lanthanide catalysts [4] (ee's up to 74\%), Ir complexes [5] (ee's up to 95\%), and Pd systems [6] (ee's up to $95 \%$ ). Recent reports have shown that $\mathrm{Ni}($ II) derivatives are able to catalyze the addition of amines to electron poor olefins: Jørgensen and co-workers catalyzed the first enantioselective addition of secondary aromatic amines to alkyl oxazolidinones with a chiral Ni(II) complex as Lewis acid [7] and the Hartwig group developed a gen-

\footnotetext{
${ }^{*}$ Correspondence: L. Fadini ETH Hönggerberg

Department of Chemistry and Applied Biosciences Wolfgang-Paulistrasse 10

$\mathrm{CH}-8093$ Zürich

Tel.: +4116334237

Fax: +4116321310

E-Mail: fadini@inorg.chem.ethz.ch

www.asymcat.ethz.ch
}

${\mathrm{R}, \mathrm{R}^{\prime}=\mathrm{H}, \mathrm{Me}}_{\mathrm{CN}}^{\mathrm{R}^{\prime}}+\mathrm{HNR}_{2} \frac{\mathrm{THF}, \mathrm{Nt}, 24 \mathrm{~h}}{\mathrm{Ti(PPP})(\mathrm{THF})]\left(\mathrm{ClO}_{4}\right)_{2}}$

Scheme 1. General catalysis with Ni(II) complexes

eral Ni(II)-catalyzed hydroamination of 1,3-dienes by alkylamines [8]. Following first-principle computational studies which indicated that Ni might be the potentially most active metal to catalyze the hydroamination via olefin activation [9], we reported the asymmetric addition of aliphatic and aromatic amines to olefins bearing electron-withdrawing groups, catalyzed by $\mathrm{Ni}(\mathrm{II})$ complexes [10]. We found that the best $\mathrm{Ni}$ catalyst, in terms of conversion and enantioselectivity, was based on the tridentate trisphosphine ligand bis $((S)-1-[(R)-2-$ (diphenylphosphino)ferrocenyl]ethyl)cyclohexyl phosphine (Pigiphos, 2). Further developments of this work include the variation of the phosphine substituents in the tridentate ferrocenyl ligand, the catalysis in ionic liquids as solvents, and the synthesis of optically active $\beta$-amino acid derivatives.

\section{Results and Discussion}

The first attempt to understand and to improve the catalytic addition of aliphatic amines to acrylonitrile derivatives (Scheme 1) involved the synthesis of modified Pigiphos ligands [11] (Scheme 2). The reported procedure for the synthesis of the tridentate ligand (from the $(R)-1-\mathrm{N}, \mathrm{N}$ dimethyl[ $(S)$-2-(diphenylphosphino)ferrocenyl]ethylamine $((R)-(S)$-PPFA, 1) derivatives and cyclohexylphosphine in acetic acid, via $\mathrm{S}_{\mathrm{N}} 1$ mechanism) gave only moderate yield (47\%). It is possible to improve the yield of this reaction simply by adding 1 equiv. of trifluoroacetic acid. Another important factor that affects the substitution is the concentration: increasing the concentration from the published $0.1 \mathrm{M}$ to a $0.5-1.0$ $\mathrm{M}(R)-(S)$-PPFA (1) in $\mathrm{CH}_{3} \mathrm{COOH}$ leads to yields up to $85 \%$.

An additional tridentate ligand was synthesized starting from the NPN ligand reported by Hayashi [12] following a procedure analogous to the one described above (see synthesis of 1,1 "-(phenylphosphinidene) bis $[(S)-2-[(R)-1-($ diphenylphosphino)ethyl] $]$ ferrocene, Gipiphos (8) in Scheme 3). The lower yield (73\%) is probably due to the lower nucleophilicity of $\mathrm{HPPh}_{2}$. 


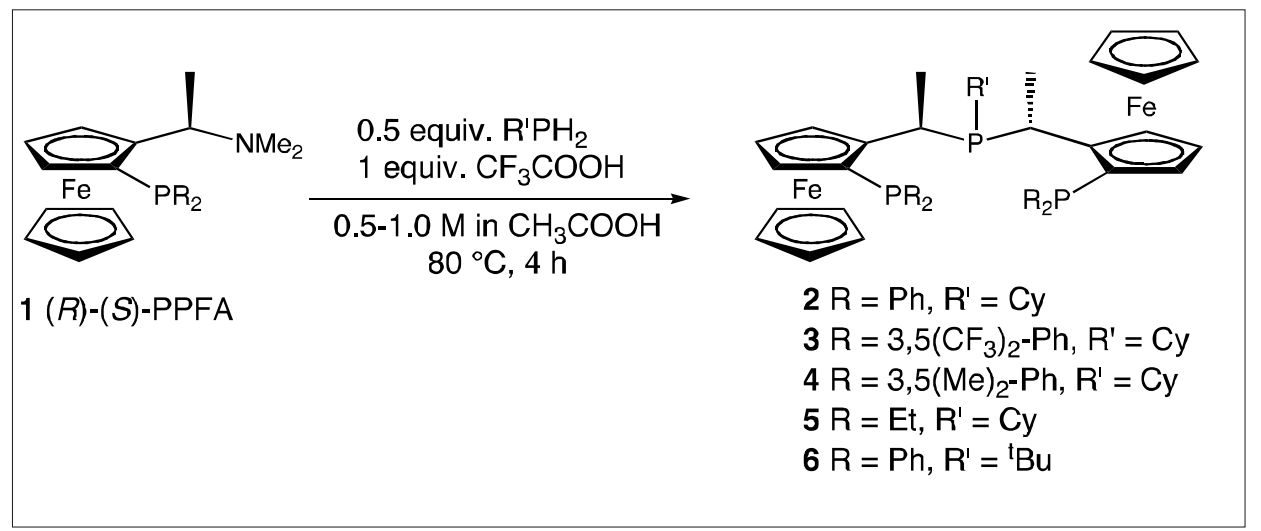

Scheme 2. Synthesis of Pigiphos ligands

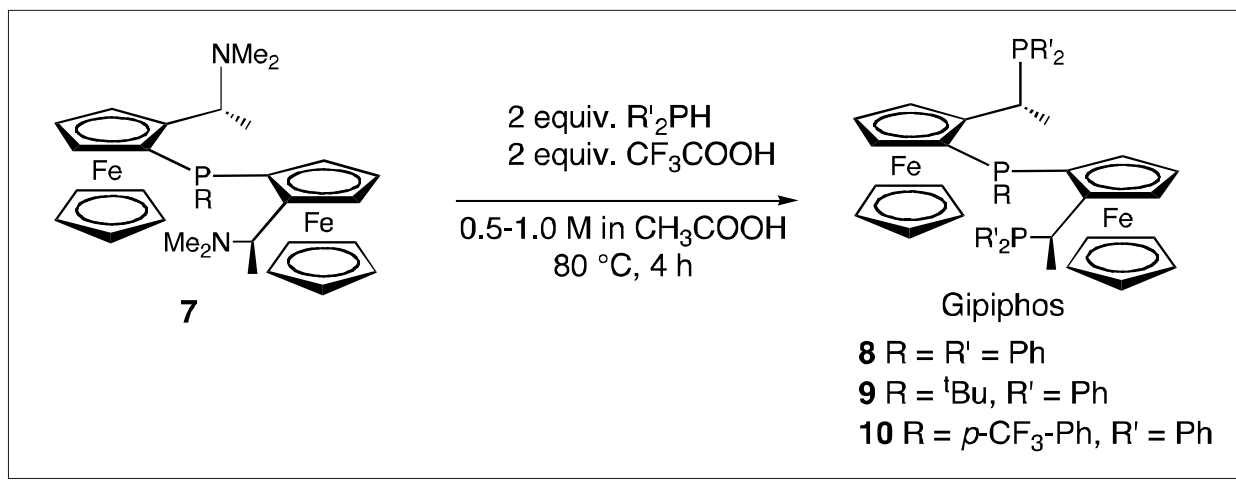

Scheme 3. Synthesis of Gigiphos ligands

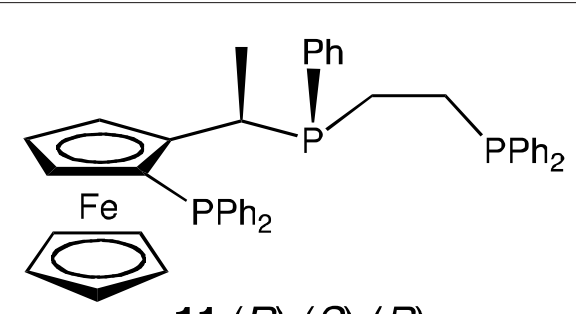

$11(R)-(S)-(R)$

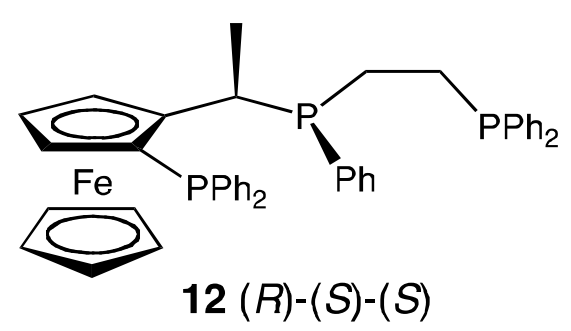

$12(R)-(S)-(S)$
Fig. 1. (R)-(S)-(R)- and (R)-(S)-(S)-PPP ferrocenyl ligands [13]

Table. Hydroamination of methacrylonitrile with morpholine ${ }^{a}$

\begin{tabular}{llll} 
Entry & Ligand & Yieldb $^{\text {ec }}$ \\
\hline 1 & $\mathbf{2} \mathrm{R}=\mathrm{Ph}, \mathrm{R}^{\prime}=\mathrm{Cy}$ & $99 \%$ & $69 \%$ \\
2 & $\mathbf{3} \mathrm{R}=3,5-\left(\mathrm{CF}_{3}\right)_{2}-\mathrm{Ph}, \mathrm{R}^{\prime}=\mathrm{Cy}$ & $43 \%$ & $9 \%$ \\
3 & $\mathbf{4} \mathrm{R}=3,5-\left(\mathrm{CH}_{3}\right)_{2}-\mathrm{Ph}, \mathrm{R}^{\prime}=\mathrm{Cy}$ & $95 \%$ & $\mathrm{rac}$ \\
4 & $\mathbf{5} \mathrm{R}=\mathrm{Et}, \mathrm{R}^{\prime}=\mathrm{Cy}$ & $90 \%$ & $5 \%$ \\
5 & $\mathbf{6} \mathrm{R}=\mathrm{Ph}, \mathrm{R}^{\prime}={ }^{\mathrm{t}} \mathrm{Bu}$ & $95 \%$ & $\mathrm{rac}$ \\
6 & $\mathbf{8} \mathrm{R}=\mathrm{Ph}, \mathrm{R}^{\prime}=\mathrm{Ph}$ & $63 \%$ & $7 \%$ \\
7 & $\mathbf{1 1}(R)-(S)-(R)-\mathrm{PPP}$ & $99 \%$ & $28 \%$ \\
8 & $\mathbf{1 2}(R)-(S)-(S)-\mathrm{PPP}$ & $99 \%$ & $36 \%$
\end{tabular}

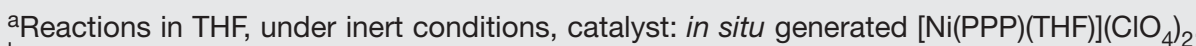
bYields are for isolated material after FC. "Enantioselectivity determined by chiral GC, $\beta$-dex, iso $92{ }^{\circ} \mathrm{C}$, ret.time $139.2 \mathrm{~min}$ and $142.7 \mathrm{~min}$.
Nickel(II) complexes of these tridentate ligands and of the two $\mathrm{P}_{3}$-chiral ones reported by Barbaro et al. [13] (Fig. 1) were used as catalysts for the addition of morpholine to methacrylonitrile. The catalysis results are summarized in the Table.

In the absence of catalyst these reactions require very high temperatures and up to now only $\mathrm{Pd}$ (II) complexes were known to catalyze them [14]. The Ni(II)-PPP complexes showed relatively high activities, reaching a TON up to 20 . The best ee's were obtained with the in situ generated Pigiphos-Ni(II) complex $\quad(69 \% \quad$ ee $)$ (Entry 1). The isolated catalyst $[\mathrm{Ni}$ (Pigiphos)(THF) $]\left(\mathrm{ClO}_{4}\right)_{2} \quad$ (synthesized from $\mathrm{Ni}\left(\mathrm{ClO}_{4}\right)_{2} \cdot 6 \mathrm{H}_{2} \mathrm{O}$ and Pigiphos (2) in THF, followed by precipitation with hexane) exhibits comparable activity and selectivity to the in situ catalyst and the remaining experiments were thus carried out under the latter conditions. We are currently investigating the structure-activity relationship [15] to understand why the modifications of the ligands $\mathbf{3}-\mathbf{5}$ did not produce any significant selectivity, and only the $\mathrm{P}_{3}$-chiral ligands displayed low enantioselectivity (Entries 7-8). However, two observations suggest the importance of tridentate ligands in this reaction. Firstly, in the less active Gipiphos-Ni(II) complex (Entry 6) the ligand apparently coordinates $\mathrm{Ni}$ in a bidentate fashion (no P-P trans coupling observed by ${ }^{31} \mathrm{P}\left\{{ }^{1} \mathrm{H}\right\}-\mathrm{NMR}$ spectroscopy). Secondly, the Ni complex containing a typical ferrocenyl bidentate ligand, Josiphos, did not afford active catalysts [10].

We have also attempted to improve the catalytic system via the use of ionic liquids as solvent (imidazolium and picolinium salts derivatives, Fig. 2) after observing counterion effects on enantioselectivity (i.e. $\mathrm{ClO}_{4}^{-}$better than $\mathrm{BF}_{4}^{-}$or $\mathrm{PF}_{6}^{-}$). In order to dissolve the $\mathrm{Ni}(\mathrm{PPP})$ complexes in the ionic liquid it was necessary to use a co-solvent (THF or acetone) which was evaporated after the complete dissolution of the Ni(II) salts. Results of the catalytic addition of morpholine to methacrylonitrile in different ionic liquids are summarized in Fig. 3 [16]. The use of ionic liquids as solvent (in 1phase or 2-phase systems) has produced results comparable to those obtained when working with THF, but with much higher activities (TONs up to 300). However, the enantioselectivities in ionic liquids and classical solvents were comparable (ee's up to $64 \%$ ). Moreover, catalysis in ionic liquids is less sensitive to air and moisture (non-distilled reagents are employed). This could result from the stabilization of the cationic species in the ionic solvent. An additional benefit of the use of ionic liquids is that the catalyst/ionic liquid mixture may be recycled.

Finally, the intermediate hydroamination products have been used for the prepa- 


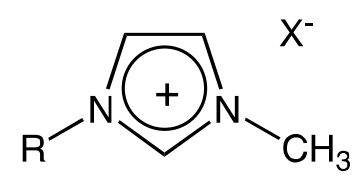

RMIM.X<smiles>[R7][n+]1cccc(C)c1</smiles>

R'PIC.Y
Fig. 2. Imidazolim and picolinium salts as ionic liquids

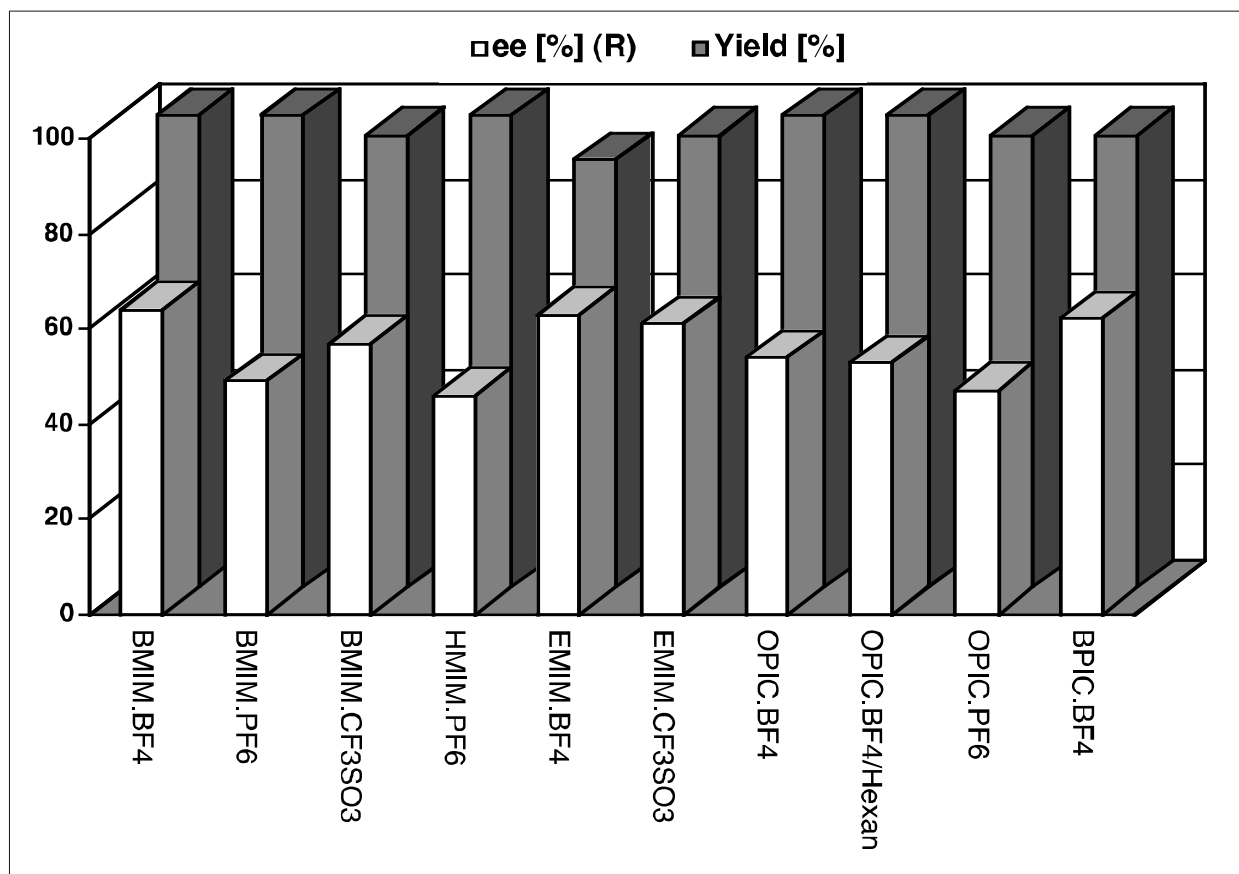

Fig. 3. Hydroamination in ionic liquids: addition of morpholine to methacrylonitrile, catalyzed by $\left[\mathrm{Ni}\left(\right.\right.$ Pigiphos)(THF)] $\left(\mathrm{ClO}_{4}\right)_{2}$ generated in situ ration of $\beta$-amino acid derivatives which are important molecules or precursors in biological and organic chemistry [17]. The product of the addition of morpholine to methacrylonitrile can be hydrolyzed with $\mathrm{NaOH} / \mathrm{H}_{2} \mathrm{O}_{2}$ to the corresponding $\beta$-amino acid. The hydrolyzed product precipitates from diethyl ether, but is soluble in water and in alcohols. The enantiomeric excess of the 2-methyl-3-(N-morpholinyl)-propionic acid is identical to that of the intermediate nitrile (Scheme 4).

Additionally, the synthesis of an unprotected amino acid was performed via the catalytic addition of benzylamine to methacrylonitrile. However, although this reaction is quantitative under the normal procedures, it afforded only 5\% ee. After hydrolysis and cleavage of the benzylic group (with $\mathrm{Pd} / \mathrm{C}$ and $\mathrm{H}_{2}$ ) it was possible to isolate the racemic 2-methyl-3-amino-propionic acid (Scheme 5).

\section{Conclusions}

Complexes of the type [Ni(PPP) $(\mathrm{L})]\left(\mathrm{ClO}_{4}\right)_{2}(\mathrm{~L}=$ solvent, $\mathrm{PPP}=$ ferrocenyl tridentate ligand) catalyze the addition of aliphatic and aromatic amines to acrylonitrile derivatives. The reaction showed comparable results in ionic liquids, where the catalysts can be recycled and prepared without inert conditions.

The hydroamination products are precursors of $\beta$-amino acids that were obtained under standard conditions for hydrolysis

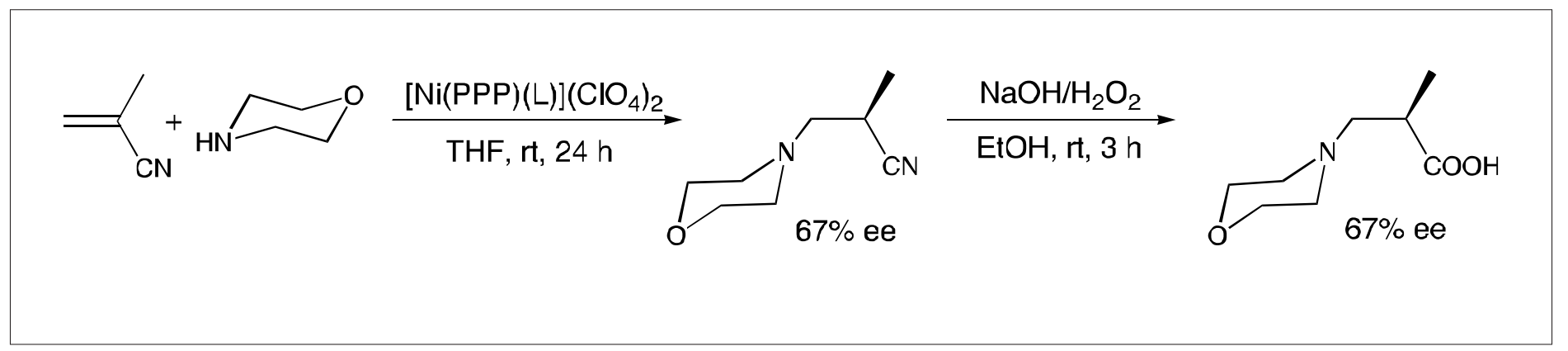

Scheme 4. Synthesis of 2-methyl-3-(N-morpholinyl)-propionic acid

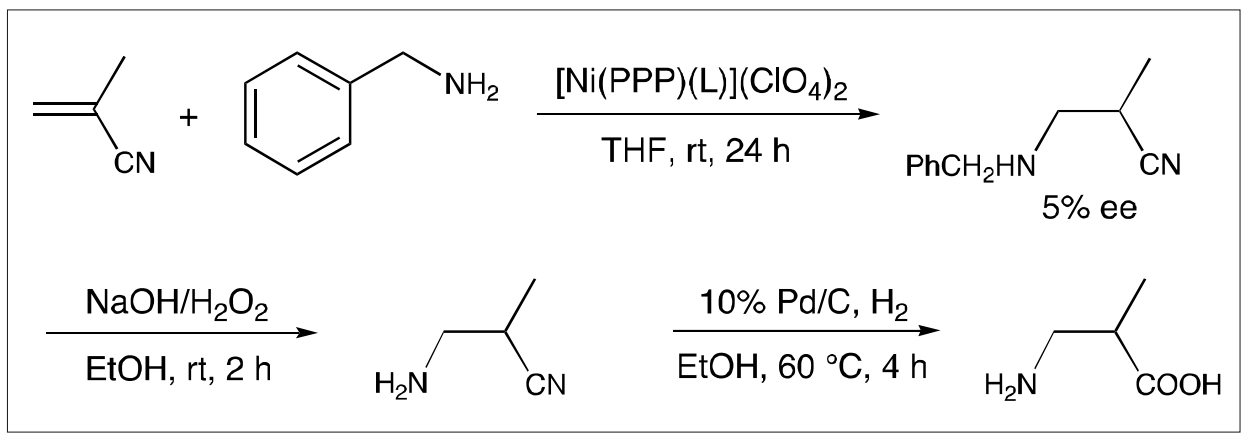

Scheme 5. Synthesis of 2-methyl-3-aminopropionic acid 
and deprotection without loss of enantiomeric excess.

\section{Acknowledgement}

We thank Lonza for the picolinium ionic liquids, P. Barbaro for the PPP chiral $^{-(R)-(S)-(S) \text { and }}$

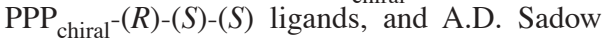
for helpful discussion about mechanistic considerations. Support from the Swiss National Science Foundation is also gratefully acknowledged.

Received: January 22, 2004

[1] J.-J. Brunet, D. Neibecker, in 'Catalytic Heterofunctionalization', Eds. A. Togni, H.J. Grützmacher, VCH, Weinheim, 2001, pp. 91.

[2] T.E. Müller, M. Beller, Chem. Rev. 1998 98, 675.

[3] P.W. Roesky, T.E. Muller, Angew. Chem. Int. Ed. 2003, 42, 2708.

[4] a) M.R. Gagne, L. Brard, V.P. Conticello, M.A. Giardello, C.L. Stern, T.J. Marks,
Organometallics 1992, 11, 2003; b) S.W. Hong, T.J. Marks, J. Am. Chem. Soc. 2002, 124, 7886; c) S.W. Hong, S. Tian, M.V. Metz, T.J. Marks, J. Am. Chem. Soc. 2003, 125, 14768; d) J.S. Ryu, G.Y. Li, T.J. Marks, J. Am. Chem. Soc. 2003, 125, 12584

[5] R. Dorta, P. Egli, F. Zürcher, A. Togni, $J$. Am. Chem. Soc. 1997, 119, 10857.

[6] a) M. Kawatsura, J.F. Hartwig, J. Am. Chem. Soc. 2000, 122, 9546; b) O. Lober, M. Kawatsura, J.F. Hartwig, J. Am. Chem. Soc. 2001, 123, 4366; c) U. Nettekoven, J.F. Hartwig, J. Am. Chem. Soc. 2002, 124, 1166; d) T. Ohmura, J.F. Hartwig, J. Am. Chem. Soc. 2002, 124, 15164; e) K.L. Li, K.K. Hii, Chem. Commun. 2003, 1132.

[7] W. Zhuang, R.G. Hazell, K.A. Jorgensen, Chem. Commun. 2001, 1240.

[8] J. Pawlas, Y. Nakao, M. Kawatsura, J.F. Hartwig, J. Am. Chem. Soc. 2002, 124, 3669.

[9] H.M. Senn, P.E. Blöchl, A. Togni, J. Am. Chem. Soc. 2000, 122, 4098.
[10] L. Fadini, A. Togni, Chem. Commun. 2003, 30

[11] P. Barbaro, A. Togni, Organometallics $1995,14,3570$.

[12] T. Hayashi, T. Mise, M. Fukushima, M. Kagotani, N. Nagashima, Y. Hamada, A. Matsumoto, S. Kawakami, M. Konishi, K. Yamamoto, M. Kumada, Bull. Chem. Soc. Jpn. 1980, 53, 1138.

[13] P. Barbaro, C. Bianchini, G. Giambastiani, A. Togni, Chem. Commun. 2002, 2672.

[14] M. Kawatsura, J.F. Hartwig, Organometallics 2001, 20, 1960.

[15] A. Sadow, A. Togni, unpublished results.

[16] L. Fadini, A. Togni, manuscript in preparation.

[17] a) G. Cardillo, C. Tomasini, Chem. Soc. Rev. 1996, 117; b) 'Enantioselective synthesis of $\beta$-Amino Acids', Ed. E. Juaristi, Wiley-VCH, New York, 1997; c) C.N.C. Drey, in 'Chemistry and Biochemistry of the Amino Acids', Ed. G.C. Barrett, Chapmann and Hall, London, 1985, p. 25. 